Original Research Article

\title{
Study of image guided fine needle aspiration cytology in cases of hepatic mass lesions
}

\author{
Sawke N. ${ }^{1}$, Madhaw N. ${ }^{2}$, Sawke G. K. ${ }^{3}$ \\ ${ }^{1}$ Dr. Nilima Sawke, Professor and Head, ${ }^{2}$ Dr. Nipun Madhaw, Post Graduate Student, ${ }^{3}$ Dr. G. K. Sawke, Professor \\ Pathology, all authors are affiliated with Department of Pathology, Chirayu Medical College \& Hospital, Bhopal, MP, \\ India.
}

Corresponding Author: Dr. Nilima Sawke, 104/C Block, Chirayu Medical College Campus, Near Bairagarh, Bhopal, India.

\begin{abstract}
Introduction: Ultrasound guided Fine needle aspiration cytology (FNAC) has been provedto be a very effective and rapid means of obtaining tissue from liver for pathological evaluation of benign, malignant and inflammatory hepatic lesions. Aims and objectives: The role of Fine needle aspiration cytology as a first line of investigation in space occupying lesions of liver and to study the various cytological patterns in hepatic lesions, categorizing them into nonneoplastic and neoplastic lesions. Materials and Methods: This was a prospective study comprising of 76 cases of liver lesions diagnosed clinically or radiologically. Abdominal ultrasonography was carried out in all cases. FNAC was performed under ultrasound guidance. Smears were stained with H \& E (Hematoxylene \& Eosin) and Wrights stain and were examined for detailed cytomorphological analysis. Results: Among 76 cases included in the study, cases of primary malignancy of liver (Hepatocellular carcinoma) were 45(59\%), and metastatic carcinomas were 21(28\%). Benign neoplastic lesions were total 4(5\%) including hepatic adenoma 3cases and 1 case of hemangioma. About 6 (8\%) cases were found to be inflammatory lesions of liver. Hepatocellular carcinoma was most common diagnosis followed by liver metastasis of adenocarcinoma. Frequency of hepatic mass lesions was almost equal in both male (39 cases) and female (37 cases) being ratio of 1:1. Conclusion: Guided FNA is a first line of investigation in space occupying lesions of liver as the procedure is safe, simple, rapid, effective and can be employed for pathological evaluation of both malignant and non-malignant hepatic lesions. Malignant tumors were the commonest of the liver lesions with highincidences of primary and metastatic deposits. On radiological examination, neoplastic and nonneoplastic lesions show overlapping features, hence cytomorphological analysis by FNAC increases the diagnostic accuracy.
\end{abstract}

Key words: Guided FNAC, Liver, Hepatocellular carcinoma

\section{Introduction}

Liver is involved in many non-neoplastic and neoplastic diseases. As sonography alone hasits limitations, cytomorphologic analysis by FNA is required to increase the diagnostic accuracy. Ultrasound guided FNA (Fine needle aspiration) of liver is safe, cheap and relativelynoninvasive procedure with minimum complications [1].

The diagnosis and management of various hepatic mass lesions is a common clinical problem and their appropriate clinical management depends on accurate diagnosis. Liver disease is the third most common cause of death among individuals between age 25 and 59 years [2].

Manuscript received: $10^{\text {th }}$ July 2018

Reviewed: $20^{\text {th }}$ July 2018

Author Corrected: $28^{\text {th }}$ July 2018

Accepted for Publication: $1^{\text {st }}$ August 2018
FNAC is a rapid, less invasive method that can beemployed for pathological evaluation of both benign and malignant hepatic lesions. Inflammatory lesions and diffuse liver diseases may mimic mass like lesions in radiographs. Such lesions can also be sampled by FNA to rule out neoplasms and differentiate it from other diagnosis [3]. The aim of the present study was to categorize the lesions of liver in to inflammatory, nonneoplastic and neoplastic lesions by ultrasound guided fine needle aspiration cytology.

\section{Material and Methods}

This is a prospective study comprising of 76 cases of liver lesions diagnosed clinically or radiologically and referred to Department of Pathology, Chirayu Medical College and hospital, Bhopal, during a period between 


\section{Original Research Article}

2016 to 2017 for cytological assessment. Investigations done before procedure were platelet count BT (Bleeding Time), CT (Clotting time) and plasma prothrombin time to know patient's with bleeding tendencies. Under ultrasonography guidance fine needle aspiration was performed on patients diagnosed for nodular or diffuse lesions of liver.

Materials used for the procedure were cotton and rectified spirit, disposable needles (22-Gauge), disposable Syringes, slides, diamond pencil, coplin jars with fixatives. Under aseptic precaution, during suspended respiration, the needle was introduced percutaneously into the lesion under ultrasound guidance. One to three passes were made. When adequate material appeared in the needle hub, the needle was withdrawn after releasing the suction pressure.

Smears were made from aspirated material. Few slides were fixed immediately in $95 \%$ alcohol and stained with $\mathrm{H} \& \mathrm{E}$ (Hemotoxylin and eosin) and Papanicoloau. Air dried smears were prepared for Wrights Geimsa stain. Stained smears were examinedunder binocular light microscope for cytological features.

\section{Result}

A total of 76 cases were studied during this duration of 1 year. Patients age group ranged from 20 to 84 years with maximum cases lying between 40 to 80 years. Out of total 76 cases 39 male and 37 were female with male to female ratio being nearly equal.

The chief complaints were pain in right upper quadrant of abdomen, weight loss, anorexia, abdominal mass and hepatosplenomegaly. Some of the patients presented with fever, pruritus, jaundice, abdominal distention and ascites.

Table-1: Age wise distribution of liver lesions.

\begin{tabular}{|c|c|c|c|c|}
\hline Age (Years) & $\begin{array}{c}\text { Primary Malignancy of } \\
\text { Liver (HCC) }\end{array}$ & $\begin{array}{c}\text { Metastatic lesions } \\
\text { of liver }\end{array}$ & $\begin{array}{c}\text { Benign lesions of } \\
\text { Liver }\end{array}$ & $\begin{array}{c}\text { Inflammatory } \\
\text { lesions of liver }\end{array}$ \\
\hline $0-20$ & - & - & - & 1 \\
\hline $21-40$ & 7 & 2 & - & 2 \\
\hline $41-60$ & 20 & 11 & 2 & 3 \\
\hline $61-80$ & 18 & 8 & 2 & 6 \\
\hline Total & 45 & 21 & 4 & - \\
\hline
\end{tabular}

Table-2: Sex wise distribution of liver lesions.

\begin{tabular}{|c|c|c|c|}
\hline Type of lesion & Male & Female & Total \\
\hline Primary malignancy & 30 & 15 & 45 \\
\hline Metastatic lesions & 6 & 15 & 4 \\
\hline Benign lesions & 1 & 3 & 6 \\
\hline Inflammatory lesions & 2 & 4 & $\mathbf{7 6}$ \\
\hline Total & $\mathbf{3 9}$ & $\mathbf{3 7}$ & 21 \\
\hline
\end{tabular}

Table-3: Spectrum of lesions of liver aspirate (Total-76 cases).

\begin{tabular}{|c|c|c|c|}
\hline S No & Type of lesion & Number of cases & Percentage \% \\
\hline 1 & Hepatocellular Ca & 45 & 59 \\
\hline 2 & Metastasis of Adenocarcinoma & 21 & 4 \\
\hline 3 & Hepatic adenoma & 3 & 1 \\
\hline 4 & Hemangioma & 1 & 8 \\
\hline 5 & Inflammatory & 6 & 28 \\
\hline
\end{tabular}




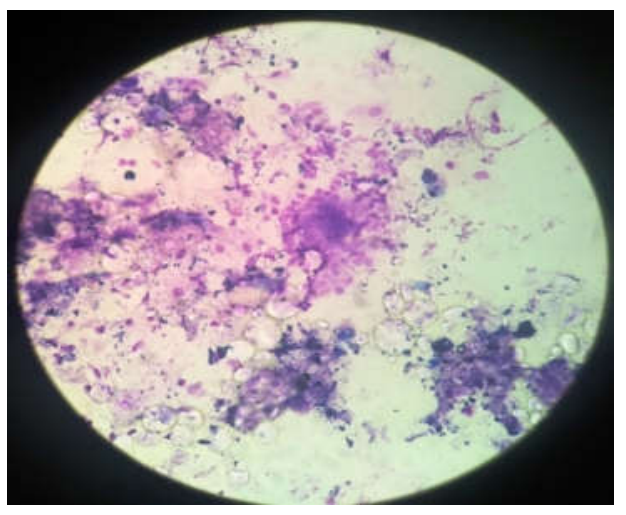

Figure 1: Malignant polygonal cells with intranuclear inclusion (Low power view)

\section{Original Research Article}

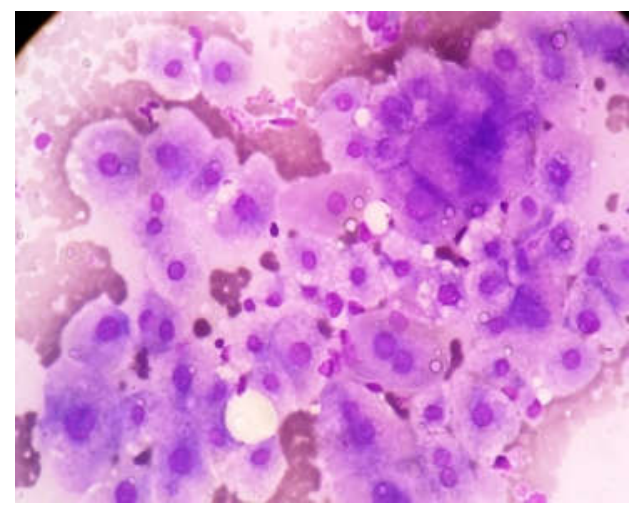

Figure 2: Malignant polygonal cells with intranuclear inclusion [High power view 400x]

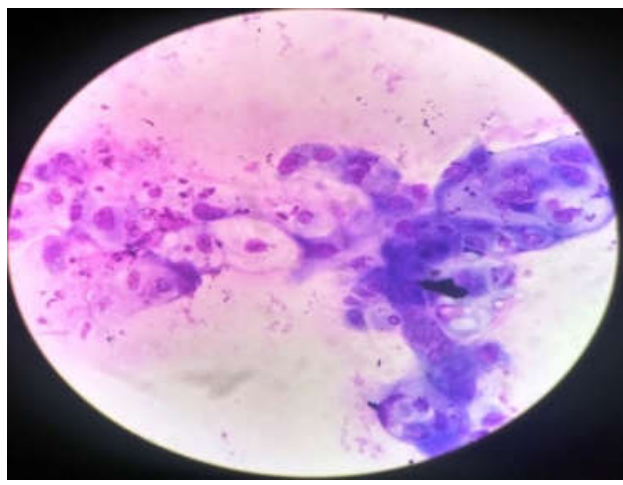

Out of total 76 cases, $45(59.2 \%)$ cases were of primary malignancy of liver and 21(27.6\%) cases were of hepatic metastasis from the primary malignancyof other organs. Other $4(5.2 \%)$ cases were benign and $6(7.89 \%)$ cases were found to be inflammatory lesions of liver.

All primary malignant tumors were hepatocellular carcinoma where as all metastatic masses were of adenocarcinoma, On ultrasound examination, solitary space occupying lesions were seen in 49(64.5\%) cases and remaining 27(35.5\%) cases were multiple or multifocal.

Out of 4 benign neoplastic lesions 3 cases were of hepatic adenoma and one case was of haemangioma. In 6 infectious lesions 4 cases of pyogenic abscess and 2 cases of tubercular abscess were seen.

\section{Discussion}

Guided FNAC is useful in accurately distinguish nonneopastic from neoplastc hepatic lesions and categorize neoplasticlesions in to primary or metastatic as concluded by Swamyet al [4].

Hepatic diseases are common entity. It affects all age groups with peak age in 5 th and $6^{\text {th }}$ decades of life [5]. In the present study patient's ageranged from 20-84 years with mean age of 54 years similar to Franca et al [6].

Zawar MP et al[7] and Shamshad et al[8] found that the incidence of malignancy increased after the age of 40 years in males and after the age of 30 years in females with a peak incidence between the ages of 40-60 years.
The most common organ which was involved in their study was the liver; In a study by Whitlach et al [9] and Wilson et al [10] Maximum number of guided aspiration were from liver showed 74 adequate smears for interpretation, out of which 27 were hepatocellular carcinoma, 29 were secondary metastasis, 1 was hepatoblastoma, 1 was hydatid cyst and 2 were liver abscesses. Remaining 14 were undifferentiated malignancy.Metastatic adenocarcinoma was commonest malignancy in secondary metastasis.

In this study FNAC results revealed predominantly malignant lesions (87\%) of which $59.2 \%$ cases were of primary malignancy of liver and $27.6 \%$ cases were of hepatic metastasis from the primary malignancy of 


\section{Original Research Article}

other organs. This is in accordance with the previous reports of similar ratio in neoplastic/non-neoplastic pathologies presenting as focal mass lesions in the liver by Hassan et al[11]. Similarly, malignant lesions out numbering benign ones were also reported by Sheikh et al [12], Sidhaling Reddy et al [13], Sumana BS et al [14].

Liver was the common sites for FNAC in this study similar to those of Tuladhar AS et al [15], Adhikari RC et al [16], and J Nobrega et al [17], In the liver, the most common malignant lesion was metastatic carcinoma.

The chief complaints of the patients were vague abdominal pain, majority of them presented with right upper quadrant pain, fatigue, weight loss, anorexia, mass per abdomen and hepatomegaly. The appropriate management of various hepatic lesions depends on accurate diagnosis [18].

High prevalence of Hepatitis $\mathrm{B}$ and $\mathrm{C}$ in Indian population, may be the reason for higher figure for malignantlesions. Other entities associated with the development of hepatocellular carcinoma include chemical carcinogens, mycotoxins, thorotrast, alpha-1antitrypsin deficiency, hemochromatosis, and long term anabolic steroid abuse. Lower rate of benign lesions in this series could be due to specific inclusion criteria.

Among the malignant lesions FNAC is also helpful to distinguish between primary liver malignancy and metastatic lesions asthe treatment modalities differ completely. The fear of major complications in FNAC of liver lesions were suspected vascular lesions and marked hemorrhage. During this study no complications were encountered.

Lundqvist and other authors have reported complications like fatal bleeding in a case of chronic liver disease, needle tract tumor seedling, biliary-venous fistula and intrahepatic hematoma, in Fine needle aspiration biopsies of the liver [19, 20].

Hepatocellular carcinoma was only primary liver malignancy in our study. Cytosmears showed malignant cell as polygonal with irregular nuclear contours and single or multiple macronucleoli, abundant eosinophilic granular cytoplasm. Intranuclear cytoplasmic inclusions and bile plugging were seen.

Cohen et al. concluded that the most important helpful cytological features were trabacular pattern, irregular granular chromatin, multiple nucleoli and atypical stripped nuclei which was similar to our study [21]. The atypical naked nuclei were included as one of the important crietaria for the diagnosis of HCC by Pedioet $a l$. as these were rarely seen in benign and metastatic conditions [22]. In present study most frequent secondary hepatic tumor were metastatic adenocarcinomas also observed by Swami MC et al[4]. Metastatic lesions of adenocarcinoma showed glandular or acinar pattern, intra and extra cytoplasmic mucin. These tumours mainly came from the GIT, breast, ovary and prostate.

\section{Conclusion}

Guided FNA is a first line of investigation in space occupying lesions of liver as the procedure is safe, simple, rapid, effective and can be employed for pathological evaluation of both malignant and non malignant hepatic lesions.

Malignant tumors were the commonest of the liver lesions with high incidences of primary and metastatic deposits. On radiological examination, neoplastic and nonneoplastic lesions show overlapping features, hence image guided cytomorphological analysis by FNAC increases the diagnostic accuracy.

\section{Contribution by authors}

- Dr Nilima and Dr Nipun conceived the idea and design of the study.

- Dr Nipun made the questionnaire and collected the data. Data interpretation and analysis was performed by Dr G K Sawke. Dr Nilima prepared the initial draft and manuscript. Consensus of all authors was reached in finalization of draft forpublication.

Funding: Nil, Conflict of interest: None initiated Permission from IRB: Yes

\section{References}

1. Gatphoh ED, Gaytri S, Babina S, Singh AM. Fine needle aspiration cytology of liver: a study of 202 cases. Indian J Med Sci. 2003 Jan;57(1):22-5.

2. Tao LC, Ho CS, Mc Loughlin MJ, et al. Cytologic diagnosis of hepatocellular carcinoma by fine-needle aspiration biopsy. Cancer. 1984 Feb 1;53(3):547-52.

3.Tsui WM, Cheng F, Lee Y. Fine needle aspiration of liver tumors. Ann Contemp Diagn Pathol1998;2:79-93.

4. Swamy MC, Arathi C, Kodandaswamy C. Value of ultrasonography-guided fine needle aspiration cytology in the investigative sequence of hepatic lesions with an emphasis on hepatocellular carcinoma. J Cytol. 2011 Oct; 28(4):178-84. doi: 10.4103/0970-9371.86344. 


\section{Original Research Article}

5.H A Nggada. Correlation between ultrasound findings and USG FNAC in the diagnosis of hepatic lesions. A Nigerian Tertiary hospital experience. The internet journal of gastroenterology. 2007; 5(2).

6. Franca AVC, Valerio HMG, Trevisan M, Escanhoela C, Pereira TS, Zucoloto S, et al. Fine needle aspiration biopsy for improving the diagnostic accuracy of cut needle biopsy of focal liver lesions. Acta Cytol 2003; 47: 332-6.

7. Zawar M.P., Dr. Bolde S., Dr. Shete S.S. Correlative study of fine needle aspiration cytology and histology in intra-abdominal lumps. SMJ 2007; 4

8. S. Shamshad Ahmed, Kafil Akhtar, S. Shakeel Akhtar et al. Ultrasound guided fine needle aspiration biopsy of abdominal masses. JK Science. 2006; 8 (4): 200-204.

9. Whitlatch S, Nuñez C, Pitlik DA. Fine needle aspiration biopsy of the liver. A study of 102 consecutive cases. Acta Cytol. 1984 Nov-Dec;28 (6): 719-25.

10. Wilson Man-shan, TsuiFung-yip Cheng,Yat-wing Lee. Fine Needle aspiration cytology of liver tumor. Annuals of Contemporary Diagnostics pathology 1998: 2:79-93

11. Hassan HS, Ahmad R. Percutaneous fine-needle aspiration biopsy cytology of liver: a review of 236 cases. Pak J Pathol1991;1:13-5.

12. Sheikh M, Sawahney S, Dev P, al-saeed O, Behbehani A. Deep- seated thoracic and abdominal masses: usefulness of ultrasound and computed tomography guidance in fine needle aspiration cytology diagnosis. Australas Radiol 2000; 44: 155 -60.

13. Sidhaling Reddy SK. Fine needle aspiration cytology of intra- abdominal lesions. Journal of Clinical and Diagnostic Research. 2011 Jun;5(3):551-8.

14. Sumana BS, Muniyappa B. Ultrasonography guided fine needle aspiration cytology with preparation of cell blocks in the diagnosis of intra -abdominal masses. Journal of clinical and diagnostic research: JCDR. 2015 Dec;9(12):EC08.

15.Tuladhar AS, Adhikari RC, Shrestha S, Sharma SK, Pradhan S, Shrestha A, Tuladhar AG. Role of USG guided FNAC in diagnosis of abdominal and thoracic lesions. Nepal Medical College journal: NMCJ. 2012 Dec;14(4):271-4

16. Adhikari RC, Tuladhar A, Shrestha S, Sharma SK. Deep -seated thoracic and abdominal lesions: usefulness of ultrasound guided fine needle aspiration cytology, a 3 year experience. Nepal Med Coll J. 2010 Mar;12(1): 20-5.

17. J Nobrega and Guimaraes dos Santos. Aspirative cytology with fine-needle in the abdomen, retroperitoneum and pelvic cavity: a seven year experience of the Portuguese Institute of Oncology, Centre of Porto. EuropeanJournal of Surgical Oncology. 1994; 20: 37-42.

18. Mingoli A, Marzano M, Sgarzini G, Nardacchione F, Corzani F, Modini C. Fatal bleeding after fi neneedle aspiration biopsy of the liver. Ital J Gastroenterol 1995; 27:250-1.

19. Lundquist A. Fine-needle aspiration biopsy for cytodiagnosis of malignant tumour in the liver. Acta Med Scand. 1970 Dec;188(6):465-70.

20. Patel RI, Shapiro MJ. Biliary venous fistula: An unusual complication of fine-needle aspiration biopsy of the liver. J VascInterv Radiol 1995;6:953-6.

21. Cohen MB, Haber MM, Holly EA, et al. Cytologic criteria to distinguish hepatocellular carcinoma from nonneoplastic liver. Am J Clin Pathol. 1991 Feb;95 (2): 125-30.

22. Pedio G, Handolt U, Zobeli U, Gut D. Fine needle aspiration of the liver. Significance of hepatocytic naked nuclei in the diagnosis of hepatocellular carcinoma. Acta Cytol 1988; 32: 437-42.

\section{How to cite this article?}

Sawke N, Madhaw N, Sawke G. K. Study of image guided fine needle aspiration cytology in cases of hepatic mass lesions. Trop J Path Micro 2018; 4(6):437-441.doi:10.17511/jopm.2018.i06.04. 